\title{
Kelimpahan dan Keanekaragaman Kupu-kupu di Kawasan Taman Nasional Gunung Merbabu, Jawa Tengah
}

\author{
Dian Ratna Sari, Mochamad Hadi dan Rully Rahadian \\ Laboratorium Ekologi dan Biosistematik, Departemen Biologi, Fakultas Sains dan Matematika, \\ Universitas Diponegoro Jl. Prof. H. Sudharto, Tembalang, Semarang.
}

\begin{abstract}
Butterflies are insects that have very important role in the ecosystem, they are as a pollinator of plants. Butterfly also can be used as a bio-indicator of environmental quality. This study aims to determine the species abundance and diversity of butterflies in the area of Merbabu Mountain National Park. This research was conducted in September and November 2016 in four habitat types, i.e., mixed forests, pine forests, mountain forests and streams. The study was conducted using a purposive sampling method. The data analysis used abundance index and diversity index. There are 454 individuals wich includes 61 species and 6 families. There are 11 dominant species of butterflies in Merbabu Mountain National Park, but only Ypthima pandocus that dominates in all the habitat that studied. Mycalesis moorei and Mycalesis sudra are dominant in all forest habitats and its not dominant in the habitat of the streams. Papilio peranthus and Parantica albata are dominant and only in mountain forest habitat. Diversity of butterflies in the area of Merbabu Mountain National Park can be categorized as moderate with the diversity index from $2,11-3,37$.
\end{abstract}

Key word: Butterflies, diversity, abundance, Merbabu Mountain National Park

\begin{abstract}
Abstrak
Kupu-kupu berperan sebagai polinator tumbuhan dalam suatu ekosistem. Hubungan antara kupu-kupu dengan tumbuhan dapat digunakan sebagai bioindikator terhadap perubahan lingkungan di kawasan TN Gunung Merbabu. Penelitian ini bertujuan untuk mengetahui kelimpahan dan keanekaragaman jenis kupu-kupu di berbagai tipe habitat di kawasan TN Gunung Merbabu. Penelitian ini dilakukan pada bulan September hingga November 2016 di empat tipe habitat yaitu hutan campuran, hutan pinus, hutan pegunungan dan aliran sungai. Penelitian dilakukan dengan metode purposive sampling. Analisis data yang digunakan yaitu indeks kelimpahan dan indeks keanekaragaman. Terdapat 454 individu yang meliputi 61 spesies dan 6 famili. Terdapat 11 spesies kupu-kupu dominan di TN Gunung Merbabu, tetapi hanya Ypthima pandocus yang mendominasi di semua habitat yang diteliti. Mycalesis moorei dan Mycalesis sudra dominan di semua habitat hutan dan tidak dominan di habitat aliran sungai. Papilio peranthus dan Parantica albata dominan dan hanya terdapat di habitat hutan pegunungan. Indeks keanekaragaman jenis kupu-kupu di kawasan TN Gunung Merbabu dikategorikan sedang dengan nilai indeks keanekaragaman 2,11-3,37.
\end{abstract}

Kata kunci: Kupu-kupu, keanekaragaman,kelimpahan, TN Gunung Merbabu.

\section{PENDAHULUAN}

Serangga di Indonesia berjumlah kurang lebih 250.000 jenis atau sekitar 14\% dari seluruh biota yang ada di Indonesia. Anggota Kelas Insekta yang memiliki jenis terbanyak adalah kumbang (Coleoptera) dan kupu-kupu (Lepidoptera). Indonesia tercatat sebagai negara dengan keanekaragaman kupu-kupu yang besar, sekitar 2500 jenis kupu-kupu (Susetya, 2014).
Total spesies kupu-kupu yang terdapat di Jawa dan Bali kurang lebih 600 jenis, 40\% diantaranya merupakan jenis endemik dan $60 \%$ lainnya merupakan jenis yang umum ditemukan di Asia Timur (Whitten et al., 1999).

Kupu-kupu memiliki peran yang sangat penting di dalam suatu ekosistem yaitu membantu penyerbukan tanaman berbunga, sehingga proses perbanyakan tanaman secara alamiah dapat 
berlangsung (Peggie, 2010). Corak sayap kupukupu yang menarik dan indah membuatnya banyak dicari dan dijadikan koleksi seni serta pola kerajinan (Borror et al., 1992). Larva kupu-kupu banyak dimanfaatkan sebagai sumber pakan di beberapa daerah (Gullan \& Craston, 2005). Kupukupu dapat pula menjadi bahan untuk kepentingan studi ilmiah (Subahar \& Yuliana, 2010).

Kupu-kupu memiliki keterkaitan erat dengan tanaman, yaitu sebagai inang, pakan dan tempat tinggal. Kupu-kupu memiliki kemampuan untuk memilih habitat guna mencari makan, kawin dan mencari tempat tinggal. Peran kupu-kupu dalam membantu penyerbukan tumbuhan membuat kupu-kupu dijadikan indikator yang baik untuk monitoring perubahan ekologi di suatu habitat karena sifatnya yang rentan terhadap adanya gangguan di lingkungan sekitar (Sreekumar \& Balakrishnan, 2001).

Taman Nasional Gunung Merbabu merupakan salah satu kawasan konservasi yang ada di Jawa. Kawasan Taman Nasional Gunung Merbabu awalnya merupakan kawasan hutan lindung seluas 5.718,5 Ha yang dikelola oleh KPH Kedu Utara dan KPH Surakarta Perum Perhutani Unit I Jawa Tengah dan kawasan Taman Wisata Alam (TWA) Umbul Songo seluas 6,5 Ha yang dikelola oleh Balai Konservasi Sumber Daya Alam (BKSDA) Jawa Tengah. Kawasan ini memiliki tipe ekosistem yang cukup beragam diantaranya yaitu ekosistem hutan hujan tropika pegunungan rendah, ekosistem hutan hujan tropika pegunungan tinggi serta ekosistem hutan sub alpin. Lokasi TN Gunung Merbabu ini berada di ketinggian 1.000$3.142 \mathrm{~m}$ dpl.

Kondisi lingkungan yang beragam ini memiliki potensi keanekaragaman jenis kupu-kupu yang juga beragam. Namun penelitian secara khusus yang mengkaji tentang keanekaragaman kupu-kupu di kawasan TN Gunung Merbabu masih sangat sedikit. Data jenis kupu-kupu yang tercatat oleh pihak TN Gunung Merbabu hanya terdapat 7 spesies (TN Gunung Merbabu, 2015). Perlu adanya penelitian mengenai keanekaragaman kupu-kupu di kawasan tersebut, sehingga keberadaan kupu-kupu yang ada dapat terpantau dan mencegah terjadinya kepunahan terutama kelompok spesies endemik. Penelitian ini bertujuan untuk mengetahui kelimpahan dan keanekaragaman jenis kupu-kupu di kawasan Taman Nasional Gunung Merbabu

\section{BAHAN DAN METODE Waktu dan Lokasi Penelitian}

Penelitian ini dilakukan pada bulan September-November 2016 di Kawasan Taman Nasional Gunung Merbabu, Provinsi Jawa Tengah. Stasiun pengamatan ditentukan pada 4 lokasi berdasarkan tipe habitat yang ada serta ditinjau dari keterjangkauan lokasi. Lokasi stasiun pengamatan yaitu Hutan campuran, Hutan pinus, Hutan pegunungan, dan Aliran Sungai. Penentuan lokasi titik pengamatan di setiap stasiun pengamatan menggunakan metode Purposive sampling, berdasarkan kondisi lokasi yang memungkinkan adanya kupu-kupu pada setiap stasiun pengamatan.

\section{Pengumpulan Data}

Pengamatan dilakukan pada puncak aktifitas kupu-kupu pada pagi hari pukul 8.00-12.00 WIB dan waktu istirahat kupu-kupu pukul 12.00-15,00 WIB. Pengamatan dilakukan pada jalur transek berdasarkan jalur setapak yang sudah ada pada masing-masing stasiun pengamatan. Panjang garis transek pada setiap stasiun pengamatan adalah $1.000 \mathrm{~m}$, dengan titik pengamatan setiap $100 \mathrm{~m}$

Pengamatan menggunakan batasan waktu yang ditetapkan secara konsisten yaitu selama 20 menit pada masing-masing titik pengamatan (Bibby, et al., 2000). Kupu-kupu yang terlihat pada tiap titik pengamatan diidentifikasi jenisnya dan dihitung jumlahnya. Pengambilan data dilakukan dengan 3 kali pengulangan. Menurut Quinn \& Klyinn (2009), jika spesies yang diamati belum diketahui jenisnya maka dilakukan penangkapan dengan jaring ayun dan pemotretan untuk dokumentasi. Kupu-kupu dimasukkan ke dalam amplop kertas papilot dan diidentifikasi lebih lanjut di Laboratorium Ekologi dan Biositematika, Departemen Biologi, Fakultas Sains dan Matematika, Universitas Diponegoro.

\section{Analisis Data}

a. Indeks Kelimpahan Jenis $\left(D_{i}\right)$

Odum (1993), gambaran kelimpahan jenis dalam suatu komunitas dapat dihitung dengan rumus: 


$$
D_{i}=\frac{n_{i}}{N} \times 100 \%
$$

Keterangan:

$D_{i}:$ Indeks kelimpahan jenis

$n_{i}$ : Jumlah individu jenis $i$

$N$ : Jumlah total individu

Menurut Helvort (1981) dalam Fachrul (2007)

$D_{i}>5 \%=$ jenis dominan.

$D_{i} 2-5 \%=$ jenis sub-dominan.

$D_{i}<2 \%=$ jenis tidak dominan.

b. Indeks Keanekaragaman Jenis $\left(H^{\prime}\right)$

Brower et al. (1997) indeks keanekaragaman jenis dihitung dengan rumus Shannon Wiener (1948):

Keterangan:

$$
H^{\prime}=-\sum p_{i} \ln p_{i}
$$

$p_{i}: \frac{n_{i}}{N}$

$H^{\prime}$ : Indeks keanekaragaman jenis

$n_{i}$ : Jumlah individu jenis $i$

$N$ : Jumlah total individu

Magurran (1988), keanekaragaman jenis dikelompokkan dalam tiga kategori, yaitu: $H^{\prime}>3,5=$ keanekaragaman jenis tinggi.

$H^{\prime} 1,5-3,5=$ keanekaragaman jenis sedang.

$H^{\prime}<1,5=$ keanekaragaman jenis rendah.

\section{HASIL DAN PEMBAHASAN}

Hasil pengamatan kelimpahan dan keanekaragaman kupu-kupu di kawasan TN Gunung Merbabu ditemukan 454 individu. Kupukupu yang ditemukan terdiri atas 61 spesies dan 6 famili, yaitu Hesperidae, Lycaenidae, Nymphalidae, Papilionidae, Pieridae dan Riodinidae. Jenis kupu-kupu yang umum dijumpai di kawasan TN Gunung Merbabu yaitu Ypthima pandocus, Mycalesis sudra, Mycalesis moorei, dan Eurema hecabe.

Kelimpahan jenis kupu-kupu di kawasan TN Gunung Merbabu sangat bervariasi di masingmasing stasiun pengamatan (Tabel 1), namun terdapat spesies yang dominan di semua stasiun pengamatan yaitu Ypthima pandocus. Kondisi ekosistem pegunungan dengan kelembaban udara tinggi (85-90\%) dan bersuhu rendah $\left(20-22^{\circ} \mathrm{C}\right)$, serta gelap dengan intensitas cahaya matahari rendah (43-131 x 100 lux) sehingga spesies dengan corak gelap banyak dijumpai. Keberadaan tanaman Eupatorium odoratum yang merupakan tanaman pakan pada seluruh tipe habitat merupakan salah satu alasan utama melimpahnya jenis Ypthima pandocus.

Mycalesis moorei dan Mycalesis sudra merupakan spesies yang dominan di habitat hutan

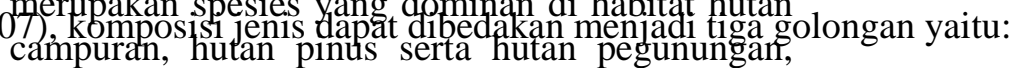
dan termasuk spesies sub dominan di habitat aliran sungai. Hal ini karena spesies ini umumnya berada di daerah yang gelap di bawah tajuk pohon yang lembab dan memiliki suhu rendah. Menurut Whitten, et al. (1999) kedua jenis kupu-kupu endemik Jawa ini umumnya ditemukan di dalam hutan primer. Kupu-kupu merupakan serangga poikiloterm sehingga suhu tubuh kupu-kupu dipengaruhi oleh suhu lingkungannya (Glassberg, 2001). Umumnya pada habitat yang tertutup tajuk memiliki jenis kupu-kupu dengan warna coklat dan corak yang cenderung gelap.

Parantica albata merupakan salah satu jenis yang dominan di hutan pegunungan. Kelimpahan jenis Parantica albata terkait dengan ketersediian tanaman pakan yaitu Eupatorium riparium. Jenis Parantica albata lebih sering dijumpai di kawasan hutan yang rimbun daripada kawasan terbuka. Anggraeni, et al., (2014) menyatakan bahwa Parantica albata merupakan jenis yang endemik di kawasan TN Bromo Tengger Semeru, jenis ini lebih menyukai kawasan hutan daripada daerah terbuka. Kupu-kupu ini merupakan jenis kupukupu endemik di Indonesia, persebarannya di Sumatra, Jawa dan Bali.

Eurema brigitta dan Eurema hecabe merupakan spesies yang dominan di habitat aliran sungai. Hal ini karena bagian tepi dari aliran sungai banyak ditumbuhi tanaman berbunga yang disukai kupu-kupu untuk mencari nektar. Tanaman yang ada di habitat ini diantaranya Eupatorium odoratum, Euphorbia hirta, Lantana camara dan Tridax procumbens. Menurut Peggie \& Amir (2006) kelompok Eurema umumnya menyukai tanaman berbunga antara lain kelompok Apocynaceae, Asteraceae dan Euphorbiaceae.

Beberapa anggota Famili Lycaenidae juga cukup dominan di habitat aliran sungai ini yaitu Udara akasa. Adanya tepian sungai yang berpasir dan basah menjadi tempat yang favorit digunakan Udara akasa untuk ber-mudpuddling secara 
berkelompok. Mereka akan menyerap garam mineral dan air dari pasir yang basah

Tabel 1. Indeks kelimpahan jenis kupu-kupu di kawasan TN Gunung Merbabu

\begin{tabular}{|c|c|c|c|c|c|}
\hline \multirow{2}{*}{ Famili } & \multirow{2}{*}{ Spesies } & \multicolumn{4}{|c|}{ Kelimpahan relatif pada Stasiun (\%) } \\
\hline & & $\mathbf{I}$ & II & III & IV \\
\hline \multirow[t]{9}{*}{ Hesperidae } & Borbo cinnara Wallace, 1866 & 0.84 & 0.56 & 0 & 2.56 \\
\hline & Caltoris malaya Evans, 1926 & 0 & 0 & 0.86 & 0 \\
\hline & Hasora Sp. & 0 & 0 & 0.86 & 0 \\
\hline & Notocrypta curvifascia C. \& R. Felder, 1862 & 0 & 0.56 & 0 & 0 \\
\hline & Notocrypta paralysos Wood-Mason \& de Nicéville, 1881 & 0 & 1.67 & 0 & 0 \\
\hline & Pseudocoladenia dan dhyana Fruhstorfer, 1909 & 0.84 & 0 & 0 & 0 \\
\hline & Taractrocera archias Felder, 1860 & 0 & 1.67 & 0.86 & 5.13 \\
\hline & Telicota augias Linnaeus, 1763 & 0 & 0 & 3.45 & 0 \\
\hline & Telicota colon Fabricius, 1775 & 3.36 & 1.11 & 0 & 0 \\
\hline \multirow[t]{4}{*}{ Lycaenidae } & Heliophorus epicles Cramer, 1780 & 5.04 & 1.11 & 3.45 & 7.69 \\
\hline & Nacaduba berenice Herrich-Schäffer, 1869 & 1.68 & 0 & 0.86 & 0 \\
\hline & Prosotas nora Felder, 1860 & 4.20 & 0.56 & 1.72 & 0 \\
\hline & Udara akasa Horsfield, 1828 & 5.04 & 0 & 0 & 7.69 \\
\hline \multirow[t]{23}{*}{ Nymphalidae } & Acraea issoria Hübner, 1816 & 0 & 3.89 & 0.86 & 0 \\
\hline & Argyreus hyperbius Linnaeus, 1763 & 0.84 & 0 & 0.86 & 2.56 \\
\hline & Athyma perius Linnaeus, 1758 & 0 & 1.11 & 0 & 0 \\
\hline & Cupha erymanthis Drury, 1773 & 0 & 0.56 & 0 & 0 \\
\hline & Cyrestis lutea Zinken, 1831 & 0 & 0.56 & 0 & 0 \\
\hline & Euploea climena Stoll, 1782 & 0 & 0.56 & 0 & 0 \\
\hline & Euploea eunice Godart, 1819 & 2.52 & 0 & 0 & 0 \\
\hline & Euploea eyndhovii C. \& R. Felder, 1865 & 0 & 0 & 0.86 & 0 \\
\hline & Euploea mulciber Cramer, 1777 & 0.84 & 0 & 0 & 0 \\
\hline & Euploea Sp. & 0 & 0.56 & 0 & 0 \\
\hline & Hypolimnas bolina Linnaeus, 1758 & 0 & 1.11 & 0.86 & 0 \\
\hline & Hypolimnas misippus Linnaeus, 1764 & 1.68 & 0 & 0 & 0 \\
\hline & Ideopsis juventa Cramer, 1777 & 0.84 & 0 & 0.86 & 2.56 \\
\hline & Junonia iphita Cramer, 1779 & 0 & 0.56 & 0 & 0 \\
\hline & Junonia orithya Linnaeus, 1758 & 0.84 & 0 & 0 & 0 \\
\hline & Lethe confusa Aurivillius, 1897 & 3.36 & 1.11 & 0.86 & 0 \\
\hline & Melanitis leda Linnaeus, 1758 & 0.84 & 0 & 0 & 0 \\
\hline & Melanitis phedima Cramer, 1780 & 0 & 1.11 & 0 & 0 \\
\hline & Mycalesis horsfieldi Moore, 1892 & 2.52 & 0 & 0 & 2.56 \\
\hline & Mycalesis janardana Moore, 1857 & 0 & 3.33 & 0 & 0 \\
\hline & Mycalesis moorei Hubner, 1818 & 2.52 & 10.00 & 10.34 & 15.38 \\
\hline & Mycalesis perseus Fabricius, 1775 & 3.36 & 0 & 0 & 0 \\
\hline & Mycalesis sudra C. \& R. Felder, 1867 & 0.84 & 13.89 & 16.38 & 15.38 \\
\hline
\end{tabular}


Neptis hylas Linnaeus, 1758

Pantoporia hordonia Stoll, 1790

\begin{tabular}{cccc}
3.36 & 1.11 & 0.86 & 0 \\
0 & 1.11 & 0 & 0 \\
0 & 0 & 0 & 5.13 \\
2.52 & 1.67 & 0 & 0 \\
0.84 & 2.22 & 2.59 & 2.56 \\
0 & 0.56 & 0 & 0 \\
0.84 & 2.22 & 0 & 0 \\
1.68 & 3.33 & 0.86 & 2.56 \\
\hline
\end{tabular}

Parantica albata Zinken, 1831

Symbrenthia anna Semper, 1888

Symbrenthia hypselis Godart, 1824

Tanaecia iapis Godart, 1824

Tanaecia palguna Cramer, 1776

1.68

Kelimpahan relatif pada Stasiun (\%)

\begin{tabular}{|c|c|c|c|c|c|}
\hline \multirow{2}{*}{ Famili } & \multirow{2}{*}{ Spesies } & \multicolumn{4}{|c|}{ Kelimpahan relatif pada Stasiun $(\%)$} \\
\hline & & I & II & III & IV \\
\hline \multirow[t]{3}{*}{ Nymphalidae } & Ypthima baldus Fabricius, 1775 & 4.20 & 0 & 0 & 0 \\
\hline & Ypthima pandocus Linnaeus, 1758 & 8.40 & 27.78 & 43.10 & 15.38 \\
\hline & Ypthima philomela Linnaeus, 1763 & 6.72 & 0 & 0 & 0 \\
\hline \multirow[t]{6}{*}{ Papilionidae } & Graphium agamemnon Linnaeus, 1758 & 0 & 0.56 & 0 & 0 \\
\hline & Graphium sarpedon Linnaeus, 1758 & 2.52 & 0.56 & 0.86 & 0 \\
\hline & Papilio helenus Linnaeus, 1758 & 2.52 & 2.22 & 0 & 0 \\
\hline & Papilio karna C. \& R. Felder, 1864 & 0.84 & 0 & 0.86 & 2.56 \\
\hline & Papilio memnon Linnaeus, 1758 & 2.52 & 2.78 & 0 & 0 \\
\hline & Papilio peranthus Fabricius, 1787 & 0 & 0 & 0 & 5.13 \\
\hline \multirow[t]{7}{*}{ Pieridae } & Appias nero Fabricius, 1793 & 0.84 & 0 & 0 & 0 \\
\hline & Cepora iudith Fabricius, 1787 & 0.84 & 0 & 0.86 & 0 \\
\hline & Delias belisama Cramer, 1780 & 0 & 1.11 & 0 & 0 \\
\hline & Eurema blanda Biosduval, 1836 & 2.52 & 1.67 & 1.72 & 0 \\
\hline & Eurema brigitta Stoll, 1780 & 6.72 & 0 & 0 & 0 \\
\hline & Eurema hecabe Linnaeus, 1758 & 7.56 & 3.89 & 4.31 & 5.13 \\
\hline & Eurema sari Horsfeld, 1829 & 1.68 & 0.56 & 0 & 0 \\
\hline Riodinidae & Zemeros flegyas Cramer, 1780 & 0.84 & 1.11 & 0 & 0 \\
\hline Jumlah & & 100 & 100 & 100 & 100 \\
\hline
\end{tabular}

Keterangan: I. Aliran Sungai, II. Hutan Campuran, III. Hutan Pinus, IV. Hutan Pegunungan Spesies dominan $\quad:>5 \%$ dari jumlah total individu

Sub-dominan $\quad: 2 \%<\mathrm{x}<5 \%$ dari jumlah total individu

Tidak dominan $\quad:<2 \%$ dari jumlah total individu

Kupu-kupu yang melalukan mudpuddling umumnya adalah kupu-kupu jantan. Garam mineral yang mereka serap tersebut akan ditransfer ke betinanya pada saat kawin, untuk menambah nutrisi bagi telur-telurnya (Glassberg, 2001). Hal ini sesuai dengan pendapat Folsom (2009) yang menyatakan habitat aliran sungai merupakan daerah yang penting bagi kupu-kupu terutama kelompok Famili Pieridae dan Lycaenidae untuk berkumpul di pasir basah di tepi sungai untuk menghisap mineral. 


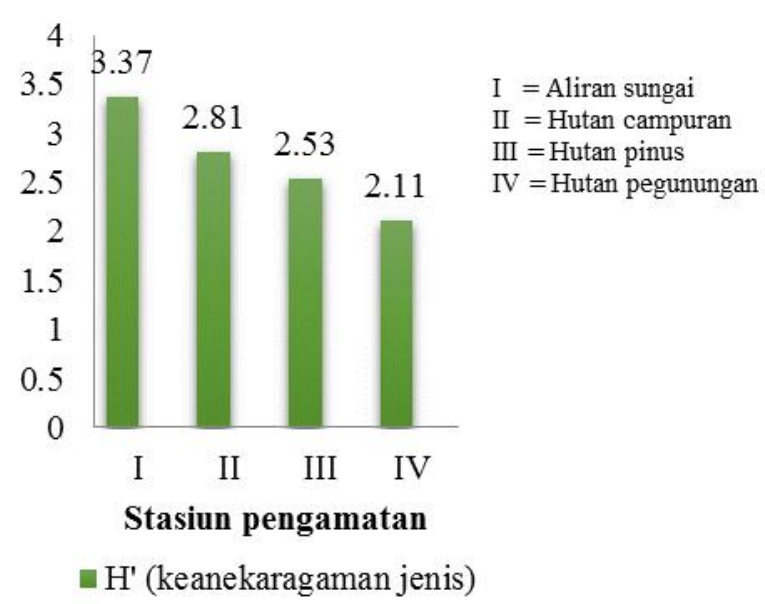

Gambar 1. Indeks keanekaragaman jenis kupu-kupu di kawasan TN Gunung Merbabu

Indeks keanekaragaman jenis kupu-kupu di kawasan TN Gunung Merbabu yaitu 2.11 - 3.37. Indeks keanekaragaman jenis kupu-kupu pada keempat stasiun pengamatan tersebut seluruhnya termasuk kategori sedang (Magguran, 1988)

Brower et al., (1997) menyatakan nilai keanekaragaman akan tinggi jika jumlah individu per jenis merata, dengan kata lain semua jenis yang terdapat dalam suatu komunitas memiliki jumlah individidu yang hampir sama. Habitat aliran sungai memiliki keanekaragaman jenis kupu-kupu yang tinggi karena adanya sumber air yang melimpah untuk mendapatkan mineral, kondisi habitat relatif lebih terbuka dengan intensitas cahaya yang lebih tinggi (177 x 100 lux) dibandingkan habitat yang lain sehingga memungkinkan kupu-kupu untuk beraktifitas dengan optimal. Sparrow et al. (1994) dalam Hamer et al., 2003, menyatakan bahwa keanekaragaman kupu-kupu berhubungan dengan intensitas cahaya, dimana semakin tinggi intensitas cahaya di suatu habitat maka keanekaragaman kupu-kupu juga semakin tinggi. Sihombing (2002) menyatakan bahwa kupu-kupu dapat hidup pada kisaran suhu $18-38^{\circ} \mathrm{C}$, dengan kelembaban udara kurang dari $85 \%$ dan intensitas cahaya yang cukup agar dapat mengepakkan sayap dan beraktifitas.

\section{KESIMPULAN}

Jenis kupu-kupu di kawasan TN Gunung Merbabu terdiri dari 61 spesies yang termasuk dalam 6 famili. Jenis yang mendominasi di TN Gunung Merbabu yaitu Ypthima pandocus, Mycalesis moorei, Mycalesis sudra dan Eurema hecabe. Keanekaragaman jenis kupu-kupu termasuk kategori sedang.

\section{UCAPAN TERIMA KASIH}

Terima kasih kami ucapakan kepada Balai Taman Nasional Gunung Merbabu yang telah memberikan izin untuk melakukan penelitian.

\section{DAFTAR PUSTAKA}

Bibby, C., M. James \& Marsden. 2000. TeknikTeknik Ekspedisi Lapangan. SMKG Mardi Yuana, Bogor.

Borror, D. J., C. A. Triplehorn \& N. F. Jhonson. 1992. Pengenalan Serangga. Penerjemah: Soetiyono. UGM Press, Yogyakarta.

Brower, J. E., J. H. Zar, \& C. N. von Ende. 1997. Field and Laboratory Methods for General Ecology, Fourth Edition. WCB/ McGrawHill, USA.

Fachrul, M. F. 2007. Metode Sampling Bioekologi. Bumi Aksara, Jakarta.

Gullan, P. J. \& P. S. Craston. 2005. The Insects: An Outline of Entomology. Blackwell Publishing Ltd., Malden.

Hamer, K. C., J. K. Hill, S. Benedick, N. Mustaffa, T. N. Sherratt, M. Maryati \& V. K. Chev. 2003. Ecology of Butterflies in Natural and Selectively Logged Forests of Northern Borneo: The Importance of Habitat Heterogenity. J. Appl Ecol. 40: 150-162.

Magurran, A. E. 1988. Ecological Diversity and Its Measurement. Princeton University Press, New Jersey.

Odum, E. P. 1993. Dasar-dasar Ekologi. 3A. Alih bahasa: Tjahjono Samingan. Gadjah Mada University Press. Yogyakarta.

Peggie, D. 2010. Kupu-kupu, Keunikan Tiada Tara. Peipusat.org-Perhimpunan Entomologi Indonesia: 1 hlm. Diakses pada http://peipusat.org/?pilih=news\& $\quad$ aksi= lihat\&id=21, tanggal 29 Maret 2016.

Quinn, M \& M. Klyinn. 2009. Butterfly Watching. Texas Park and Wildlife, Texas.

Sihombing. 2002. Satwa Harapan I Pengantar Teknologi Budidaya. Pustaka Wirausaha Muda, Bogor. 
Sreekumar, P. G. \& M. Balakrishnan. 2001. Habitat and Altitudine Preference of Butterfly in Aralam Wildlife Sanctuary. Kerala, Tropical Ecology. Vol.42: 227-281.

Subahar, T. S. S. \& A. Yuliana. 2010. Butterfly Diversity as A Database for The Development Plant of Butterfly Garden at Bosscha Observatory, Lembang, West Java. Jurnal Biodiversitas. 11 (1): 24-28.

Susetya, R. S. A. 2014. Keanekaragaman KupuKupu Diurnal (Sub Ordo: Rhopalocera) di Komplek Gunung Bromo KPH Surakarta, Kab. Karanganyar Tahun 2013. Naskah
Publikasi. Pendidikan Biologi, Fakultas Keguruan dan Ilmu Pendidikan Universitas Muhammadiyah Surakarta, Surakarta.

TN Gunung Merbabu. 2015. Statistik Balai Taman Nasional Gunung Merbabu Tahun 2015. Balai Taman Nasional Gunung Merbabu, Boyolali.

Whitten, T., R. E. Soeriaatmadja \& S. A. Afiff. 1999. Ekologi Jawa dan Bali. Prenhallindo, Jakarta. 